\title{
Stability of cosmetic formulations containing UV filters and preservatives, based on physical and chemical parameters
}

\begin{abstract}
Cosmetic stability predictions one of the key parameter for good quality of the product and is essential to assure the efficiency of the preservative system, and consumer safety. This study proposes the determination of cosmetics chemical stability validated by chromatography and physical measurements. Physical and organoleptic stability, important parameters in skin care products are also considered in this work. Twelve cosmetic products were stored at $25^{\circ} \mathrm{C}$ and $45^{\circ} \mathrm{C}$ during three months. According to organoleptic results, five formulas on twelve showed signs of degradation and physical instability, that can turn into unattractive product and damage their image. The same formulas have shown significant $\mathrm{pH}$, viscosity and modifications. Chemical degradation and toxic byproduct identification are evaluated by analytical assay. According to analytical results, no concentration decreases have been observed for UV filters, contrary to some preservatives. First decrease has appeared for methyl paraben at Day 40 at room temperature (RT) and at Day 19 at $45^{\circ} \mathrm{C}$, a $10 \%$ diminution has been observed.
\end{abstract}

This decrease can have consequences on microbial safety by proliferation of microorganisms and cause skin infections after application. By the large range of product forms studied in these experimentations, the need to choose the best criteria for each formula, before any study of stability, appeared as obvious. Regarding the type of formula and the ingredient, oxidation and degradation of urea have been identified as being responsible for instability. Identification of these reactions demonstrates that determination of chemical reactions in cosmetic safety evaluation and determination of the shelf life of a product have to be studied to ensure safety. For two critical formulas: body scrub and moisturizer, theoretical period after open (PAO) were confronted with experimental determination and have not been proven. Finally, in regard to active compounds studied: methylparaben, propyl paraben, salicylic acid and benzoic acid showed diminution of concentration in time contrary to UV filters.

Keywords: Cosmetics, UV filters, Preservatives, Physical, Chemical stability
Volume I Issue I - 2015

\section{Pirnay Stephane}

Expertox University, France

Correspondence: Pirnay Stephane, Expertox University, I 4 rue Godefroy Cavaignac Paris 750 I I, France, Tel 33 (0)981078503, Email expertoxcom@gmail.com

Received: August II, 2014 | Published: January 27, 2015
Abbreviations: ANT-D10, anthracen-d10; BA, benzoic acid; BAL, benzyl alcohol; BBD, best before date; BEMO, bemotrizinol; BENZO4, sulisobenzone; CHLOR, chlorphenesin; $\mathrm{CV}$, coefficient of variation; D, day; GC, gas chromatography; LC, liquid chromatography; MP, methylparaben; NSAM, national security agency of medicines and health products; OCTO, octocrylene; PAO, period after open; PHE, phenoxyethanol; PP, propyl paraben; RT, room temperature; SA, salicylic acid; SCCS, scientific committee on consumer safety; THF, tetrahydrofuran

\section{Introduction}

From manufacture to final consumer, cosmetic products are subject to various factors influencing their stability such as exposure to varying degrees of light, temperature, humidity, and packaging material. All these factors have an impact on organoleptic, physicochemical properties and microbiological aspect. It is important to guarantee quality by paying attention to the time required to distribute the product from the manufacturer to the consumer and evaluate the usage period. According to cosmetic Regulations 1223/2009 the manufacturer must mention two types of dates on the product: Best before Date (BBD) and Period after Open (PAO) except for single dose, pressurized aerosol-type forms, and anhydrous products. ${ }^{1}$ No text regulates the procedures applicable to the validation of a BBD or
PAO. Cosmetics Europe, Scientific Committee on Consumer Safety (SCCS), National Security Agency of Medicines and Health Products (NSAM), and finally the European Commission, provide guidelines, but the conditions of study, the factors tested, the parameters evaluated remains to the discretion of the responsible person. To be face to the dynamics market and development of new products, stability prediction is usually performed by accelerated storage conditions. ${ }^{2,3}$ To ensure the function of the active formula, the first stage is to observed changes in their physico-chemical properties: odor change, color fading, fragrance changes, staining, separation, sedimentation. However, degradation of active compounds, their concentrations in the formula and identification of toxic byproducts cannot be evaluated by physical observations. Many reactions can generate byproduct, for example, a benzophenone photo product was identified as 2 , 4-dimethylanisole. ${ }^{4}$ Many publications studied the active compound on cosmetics product and their degradation, by different experimental techniques. Inorganic filters are determined by AAS in the flame. ${ }^{5}$

Organic filters are determined by spectroscopy NMR, Raman spectroscopy, absorption spectroscopy, UV-Vis, gas chromatography (GC), liquid chromatography (HPLC). ${ }^{6-12}$ Moreover, the link between physico-chemical degradations and molecular degradation is hardly evaluated. A work in 2006 by Thais Guaratini et al., ${ }^{13}$ describe the determination of gel-cream stability by chemical and physical 
parameters validated by (HPLC) chromatography and rheological measurements, conclusion confirm that chemical and physical stability must be evaluated at the same time since they seem to have related effects. Other works have been studied stability of new formulation..$^{14,15}$ In the present work the influence of temperature on the stability of twelve cosmetic formulations is evaluated. Temperature storage tests were performed to accelerate the aging process and evaluate the stability during three month. The aim of this study is to evaluate chemical and physical parameters for stability determination in cosmetic formulations, using several products with various cosmetic forms. The results should contribute to a better understanding of physical and chemical stability aspects of cosmetic formulations under the influence of temperature and conclude on the accelerated condition $\left(45^{\circ} \mathrm{C}\right)$ compare to normal condition (room temperature).

\section{Materials and methods}

\section{Standards, reagents and solvents}

All solvents were of analytical grade or of HPLC grade. The selected compounds used in the present work are: Octocrylene (OCTO), Sulisobenzone (BENZO4), Bemotrizinol (BEMO), Benzoic Acid (BA), Salicylic Acid (SA), Chlorphenesin (CHLOR), Phenoxyethanol (PHE), Methylparaben (MP), Propyl paraben (PP), and Benzyl Alcohol (BAL) were acquired from Sigma-Aldrich. Internal standard: Anthracen-d10 (ANT-D10), were supplied by Sigma-Aldrich. Solvents: Methanol, Ethanol, Acetonitril, Acetic Acid, Tetrahydrofuran (THF) were supplied by VWR and Servilab. Purified water from Milli-Q was used (Millipore).

\section{Sample}

Twelve different formulations: body scrub, shower gel, body oil, body cream, cleansing gel, baby shower gel shampoo, lotion, solar spray, moisturizer, lipstick, mascara, and nail polish, for various applications: body, hair, eyes, lips were studied. They were obtained by cosmetic formulation laboratories. The list of the products and active compounds studied are represented in (Table 1).

\section{Apparatus}

The $\mathrm{a}_{\mathrm{w}}$ (water activity) was measured with a NovasinaLab-Swift$\mathrm{a}_{\mathrm{w}}$ (sensitivity: \pm 0.01 ), $\mathrm{pH}$ was measured with a $\mathrm{pH}$-meter $3110 \mathrm{WTW}$ (sensitivity: \pm 0.255 ), the centrifuge stability was measured with Rota fix $32 \mathrm{~A}$ at $3000 \mathrm{rpm}$ for 20 minutes, and the viscosity (precision: $\pm 500 \mathrm{cp}$ ) was performed by a Brookfield model viscometer with spindle S-69.

\section{LC/UV conditions}

The liquid chromatography was performed by an Agilent 1220 Infinity LC system including a degasser and a variable wavelength UV/Vis detector, connected to Open Lab Station. The LC columns were a ZORBAC Eclipse plus C18 $(4.6 \mathrm{mmx} 150 \mathrm{~mm}, 3.5 \mu \mathrm{m})$ and a Polaris 5 C18-A $(4.6 \mathrm{mmx} 150 \mathrm{~mm}, 5 \mu \mathrm{m})$ especially for Benzoic Acid (BA) and Salicylic Acid (SA). Five liquid chromatography independent methods, used for quantification of: BEMO, BENZO4, OCTO, BA, SA, CHLOR, PHE, PP and MP are listed in (Table 2).

\section{GC/MS conditions}

Benzyl alcohol chromatographic quantification was performed by Agilent $7890 \mathrm{a} / 5975 \mathrm{C}$ inert $\mathrm{GC} / \mathrm{MSD}$ system with an auto sampler Gerstel (MPS 2 XL), and a column Agilent DB-5MS
$(30 \mathrm{~m} \times 250 \mu \mathrm{m} \times 0.25 \mu \mathrm{m})$. The internal standard was ANT-D10. Quantification was achieved in 34 minutes with helium as the carrier gas at a constant flow rate of $1.0 \mathrm{~mL} \cdot \mathrm{min}^{-1}$. The oven temperature was $280^{\circ} \mathrm{C}$. A $1 \mu 1$ aliquot was injected in split less mode. The MS source and quadruple temperatures were set at $230^{\circ} \mathrm{C}$ and $150^{\circ} \mathrm{C}$ respectively. Mass spectra were obtained in SIM mode: quantifier ion $\mathrm{m} / \mathrm{z}$ is 108 and the qualifier ions $\mathrm{m} / \mathrm{z}$ is 51,77 and 79 .

Table I Cosmetics products and active compounds studied

\begin{tabular}{lll}
\hline Cosmetic sample & Active compound studied & Quantity (\%) \\
\hline Body scrub & AB & 0.5 \\
Shower gel & BA & 0.02 \\
Body oil & I & $/$ \\
Body cream & PHE & 0.64 \\
& CHLOR & 0.16 \\
Cleansing gel & CHLOR & 0.1 \\
& PP & 0.0003 \\
Baby shower gel & CHLOR & 0.2013 \\
shampoo & AS & 0.0054 \\
Lotion & BENZO4 & 0.3 \\
Solar spray & BEMO & 0.2 \\
OCTO & PP & 2 \\
Moisturizer & MP & 4 \\
Lipstick & PHE & 0.156 \\
Mascara & PHE & 0.212 \\
\hline & $/$ & 0.10 \\
\hline
\end{tabular}

\section{Stability studies}

Twelve cosmetic products were studied in this work. They were stored for 12 weeks at RT $\left(25^{\circ} \mathrm{C}\right)$ and $45^{\circ} \mathrm{C}$, in a glass jar $(30 \mathrm{~mL})$. Three types of stability were investigated: organoleptic, physical, and chemical stability. Four organoleptic criteria were observed: general appearance, color, and odor and phase difference after 20 minutes at 3000rpm. Three physical tests were performed: $\mathrm{pH}$, aw and viscosity. $\mathrm{pH}$ and viscosity were performed in triplicate, and $\mathrm{a}_{\mathrm{w}}$ was performed in a single measurement. Chromatographic determinations were performed in duplicate. Chromatographic determinations were performed twice a week during the first 7 weeks and once a week during the last five weeks. The time table is presented in (Table 3). All tests weren't applicable to all products. Table 4 presents the list of applicable and not applicable tests for each product.

\section{Extraction of UV filters and preservatives from cosmetic sample}

General extraction: About 1g of cosmetic product was weighed into a plastic falcon tube, $10 \mathrm{~mL}$ of methanol was added, vortexed and immersed for 30 minutes in an ultrasonic bath heated at $60^{\circ} \mathrm{C}$ to melt 
any lipid phase and to facilitate the extraction of active components into methanol phase. Then the tube was centrifuged for 20 minutes at 3000rpm. The supernatant was filtered with $4 \mu \mathrm{m}$ filter and $1 \mathrm{~mL}$ volume of the supernatant was introduced in sample vial. Some matrixes have to be diluted to fit with the validated line a regression curve.

Table 2 Chromatographic conditions and validation parameters for five quantification methods

\begin{tabular}{|c|c|c|c|c|c|c|c|c|c|c|c|c|c|c|c|c|}
\hline Compounds & \multicolumn{3}{|c|}{ BENZO4 and BEMO } & ОСТО & & \multicolumn{4}{|c|}{ BA and SA } & \multicolumn{3}{|c|}{ CHLOR and PHE } & $P$ and & & & \\
\hline \multicolumn{17}{|c|}{ Chromatographic conditions } \\
\hline \multirow{5}{*}{ Solvent } & \multicolumn{3}{|c|}{ A:Water } & \multicolumn{2}{|c|}{ A:Water } & \multicolumn{5}{|c|}{$\begin{array}{l}\text { A:Water + } 0.1 \% \text { Acetic } \\
\text { acid }\end{array}$} & \multicolumn{2}{|c|}{ A :Water } & \multicolumn{4}{|c|}{ A:Water } \\
\hline & \multicolumn{3}{|c|}{ B: Ethanol } & \multicolumn{2}{|c|}{ B: Methanol } & \multicolumn{5}{|c|}{ B:Acetonitrile } & \multicolumn{2}{|c|}{ B: Methanol } & \multicolumn{4}{|c|}{ B: Methanol } \\
\hline & Time & $\mathrm{A}(\%)$ & $\mathrm{B}(\%)$ & Time & $\mathrm{A}(\%)$ & $\mathrm{B}(\%)$ & Tin & & $\mathrm{A}(\%)$ & $\mathrm{B}(\%)$ & Time & $A(\%)$ & $\mathrm{B}(\%)$ & & & \\
\hline & 0.00 & 0 & 100 & 0.00 & 30 & 70 & 0.0 & & 50 & 50 & 0.00 & 50 & 50 & Time & $A(\%)$ & $\mathrm{B}(\%)$ \\
\hline & & & & & & & & & & & 6.00 & 50 & 50 & & & \\
\hline \multirow{5}{*}{ Time Table } & 3 & 0 & 100 & 6 & 10 & 90 & 10 & & 50 & 50 & 8.5 & 25 & 75 & 0 & 40 & 60 \\
\hline & 4 & 50 & 50 & 16 & 10 & 90 & & & & & 10 & 0 & 100 & 15 & 40 & 60 \\
\hline & 5 & 50 & 50 & 3 & 30 & 70 & & & & & 12 & 0 & 100 & & & \\
\hline & 8 & 0 & 100 & & & & & & & & 14 & 90 & 10 & & & \\
\hline & 9 & 0 & 100 & & & & & & & & 6 & 90 & 10 & & & \\
\hline $\begin{array}{l}\text { Injection } \\
\text { Volume }(\mu \mathrm{L})\end{array}$ & \multicolumn{3}{|l|}{20} & 20 & & \multicolumn{4}{|c|}{10} & \multicolumn{3}{|c|}{5} & \multicolumn{3}{|c|}{5} & \\
\hline $\begin{array}{l}\text { Flow Rate } \\
(\mathrm{mL} / \mathrm{min})\end{array}$ & \multicolumn{3}{|l|}{ I } & 1 & & \multicolumn{4}{|c|}{2} & \multicolumn{3}{|c|}{0.6} & \multicolumn{3}{|c|}{0.8} & \\
\hline $\begin{array}{l}\text { Inject Speed } \\
(\mu \mathrm{L} / \mathrm{min})\end{array}$ & \multicolumn{3}{|l|}{200} & 200 & & \multicolumn{4}{|c|}{200} & \multicolumn{3}{|c|}{200} & \multicolumn{3}{|c|}{200} & \\
\hline \multicolumn{17}{|l|}{ Acquisition } \\
\hline $\begin{array}{l}\text { Time } \\
\text { (minutes) }\end{array}$ & 9 & & & 19 & & & 10 & & & & 16 & & & 15 & & \\
\hline $\begin{array}{l}\text { Wavelength } \\
(\mathrm{nm})\end{array}$ & 310 & & & 300 & & & 25 & & & & 280 & & & 254 & & \\
\hline & & & & & $\mathbf{V a l}$ & ation $\mathbf{p}$ & ram & ete & & & & & & & & \\
\hline $\begin{array}{l}\text { Linearity Range } \\
(\mu g / \mathrm{mL})\end{array}$ & & 500 & & $50-500$ & & $5-100$ & & & 500 & & & & & & & \\
\hline LOD $(\mu g / m L)$ & I & & & 10 & & 1 & & 10 & & I & & & & & & \\
\hline LOQ ( $\mu \mathrm{g} / \mathrm{mL})$ & 5 & & & 50 & & 5 & & 50 & & 5 & & & & & & \\
\hline$r^{2}$ & & $\begin{array}{l}\sqrt{ } \mathrm{ZO} 4: \\
10: 0 .\end{array}$ & $\begin{array}{l}.9946 \\
968\end{array}$ & ОСТО : 0.99 & & $\begin{array}{l}A B: \\
0.9981 \\
A S: 0.9\end{array}$ & & & $\begin{array}{l}\text { ILOR : } \\
997 \\
E: 0.9997\end{array}$ & & $\begin{array}{l}: 0.9997 \\
: 0.9999\end{array}$ & & & & & \\
\hline
\end{tabular}

BA, benzoic acid; BAL, benzyl alcohol; BEMO, bemotrizinol; BENZO4, sulisobenzone; CHLOR, chlorphenesin;

MP, methylparaben; NA, not applicable; OCTO, octocrylene; PHE, phenoxyethanol; PP, propyl paraben; RT, room temperature; SA, salicylic acid; $\mathrm{V}$, viscosity

Table 3 Time table for sampling

\begin{tabular}{|c|c|c|c|c|c|c|c|c|c|c|c|c|c|c|c|c|c|c|c|c|}
\hline Week & Ist & & & 2nd & & 3rd & & 4th & & 5th & & 6th & & 7th & & 8th & 9th & I0th & IIth & I 2th \\
\hline \multicolumn{21}{|c|}{ Organoleptic and physicochemical } \\
\hline Days & 0 & 4 & 7 & II & 14 & 18 & 21 & 25 & 29 & 32 & 35 & 39 & 42 & 46 & 49 & 53 & 61 & 68 & 75 & 82 \\
\hline \multicolumn{21}{|c|}{ Analytical } \\
\hline Days & 0 & 5 & 8 & 12 & 15 & 19 & 23 & 26 & 30 & 33 & 36 & 40 & 43 & 47 & 50 & 56 & 62 & 69 & 76 & 83 \\
\hline
\end{tabular}


Table 4 Applicable tests to products

\begin{tabular}{|c|c|c|c|c|c|c|c|}
\hline Cosmetic samples & General appearance & Odor & Color & Phase difference & $\mathrm{pH}$ & $a_{w}$ & Viscosity \\
\hline Body scrub & $x$ & $x$ & $x$ & $x$ & $x$ & $x$ & NA \\
\hline Shower gel & $x$ & $x$ & $x$ & NA & $x$ & $x$ & $x$ \\
\hline Body oil & $x$ & $x$ & $x$ & NA & NA & NA & NA \\
\hline Body cream & $x$ & $\mathrm{x}$ & $x$ & $x$ & $x$ & $x$ & NA \\
\hline Cleansing gel & $x$ & $x$ & $x$ & $x$ & $x$ & $x$ & $x$ \\
\hline Baby shower gel shampoo & $x$ & $x$ & $x$ & $x$ & $x$ & $x$ & $x$ \\
\hline Lotion & $x$ & $x$ & $x$ & NA & $x$ & $x$ & NA \\
\hline Solar spray & $x$ & $x$ & $x$ & $x$ & $x$ & $x$ & $x$ \\
\hline Moisturizer & $x$ & $x$ & $x$ & $x$ & $x$ & $x$ & $x$ \\
\hline Lipstick & $x$ & $x$ & $x$ & NA & NA & NA & NA \\
\hline Mascara & $x$ & $x$ & $x$ & NA & NA & NA & NA \\
\hline Nail Polish & $x$ & $x$ & $x$ & NA & NA & NA & NA \\
\hline
\end{tabular}

Phenoxyethanol extraction from lipstick: About $0.5 \mathrm{~g}$ of the lipstick of the products. However, at $45^{\circ} \mathrm{C}$, color has changed for: body scrub, was weighed into a plastic falcon tube; $5 \mathrm{~mL}$ of acetone was added. shower gel, lotion and body cream. Body scrub has changed in a first The same protocol was applied for the extraction procedure. Benzyl time at D14 by the disappearance of white grains, and paste turned alcohol extraction from body cream: About $1 \mathrm{~g}$ of body cream was darker at D32. Other color modifications appeared between D46 and weighed into a plastic falcon tube, $10 \mathrm{ml}$ of THF was added, the D53. For shower gel, the turquoise-blue color was turned to green. solution was vortexed for 10 minutes and stored at $4{ }^{\circ} \mathrm{C}$ in order to clot For lotion, transparent liquid was turned yellow. For body cream, the the oil. Then the tube was centrifuged for 30 minutes at $6000 \mathrm{rpm}$. The original pistachio color was turned darker (Figure 1B).

supernatant was filtered with $4 \mu \mathrm{m}$ filter and $1 \mathrm{ml}$ was evaporated, the residue was redissolved in $1 \mathrm{~mL}$ de methanol.

\section{Data analysis}

Odor: Odor modification has appeared only in moisturizer. This product released a strong and spicy ammoniac odor at $45^{\circ} \mathrm{C}$ and $\mathrm{RT}$ in D14 and D21 respectively (Figure 1C).

Graph Pad Prism $6^{\circledR}$ was used to graphic representation and Phase separation: Four of the six products have shown phase statistical analysis. The means of the triplicate and duplicate measures separation after centrifugation. Phase separation occurred at both $45^{\circ} \mathrm{C}$ and/or concentrations were presented with Standard Error of the Mean (SEM).

\section{Results and discussion}

\section{Organoleptic results}

Four organoleptic properties were studied: General appearance (Figure 1A), color (Figure 1B), odor (Figure 1C), and phase difference (Figure 1D). They were monitored at RT and $45^{\circ} \mathrm{C}$. Organoleptic modifications were identified in six of the twelve products:
a. Body scrub
b. Body cream
c. Solar spray
d. Moisturizer
e. Lotion and shower gel

General appearance: Modifications were not observed at room temperature in any of the products. However, at $45^{\circ} \mathrm{C}$, general appearance has changed for: body scrub, body cream, solar spray, and moisturizer. Grains got smaller for body scrub (at D14) and totally disappeared at D61. For solar spray and moisturizer, fluidity changes were observed at D49 and D61 respectively, to the naked eye, they have become more liquid. Body cream was subjected to phase separation at D21: liquid on the top, solid phase at the bottom (Figure 1A).

Color: Modifications were not observed at room temperature in any and RT for body scrub on D39 and D42 respectively. However, phase separation occurred at $45^{\circ} \mathrm{C}$ for the remaining three products (Figure 1D). For body cream and moisturizer, an oil phase appeared on the top at $45^{\circ} \mathrm{C}$. For the solar spray, a small yellow droplet appeared at the bottom at $45^{\circ} \mathrm{C}$. For body scrub, three parts were observed: crumbly at the bottom, smooth paste in the middle and oil on top. The oil phase was bigger, and the others phases decreased in time. Refer to (Figure 1) for specific days. In summary, body scrub has shown three modifications on four criteria: general appearance, color, and phase separation. General appearance and color modifications have appeared at $45^{\circ} \mathrm{C}$ only, at D14. Phase separation has appeared at both $45^{\circ} \mathrm{C}$ and RT at D39 and D42 respectively. Body cream also has shown three modifications on four criteria: general appearance, color, and phase separation. General appearance and phase difference have appeared at D21. Color modification has appeared at D46. Moisturizer has presented modification on criteria general appearance, odor, and phase difference. Only at $45^{\circ} \mathrm{C}$ for general appearance and phase separation. At $45^{\circ} \mathrm{C}$ and RT for odor with a delta of 1 week.

a) Lotion showed modification at $45^{\circ} \mathrm{C}$ for criteria color.

b) Shower gel showed modification at $45^{\circ} \mathrm{C}$ for criteria color.

c) Solar spray showed modification at $45^{\circ} \mathrm{C}$ for criteria phase separation.

According to the first results, five formulas presented signs of degradation and physical instability: body scrub, body cream, moisturizer, lotion and solar spray that can transform the product unattractive and damage their image. 


\begin{tabular}{|c|c|c|c|c|c|c|c|c|c|c|c|c|c|c|c|c|c|c|c|c|c|}
\hline \multirow{3}{*}{ PRODUCTS } & \multirow[b]{3}{*}{$\mathrm{T}^{\circ}\left({ }^{\circ} \mathrm{C}\right)$} & \multirow{2}{*}{\multicolumn{20}{|c|}{ DAYS }} \\
\hline & & & & & & & & & & & & & & & & & & & & & \\
\hline & & 0 & 4 & 7 & 11 & 14 & 18 & 21 & 25 & 29 & 32 & 35 & 39 & 42 & 46 & 49 & 53 & 61 & 68 & 75 & 83 \\
\hline \multirow{2}{*}{ Body scrub } & RT & & & & & & & & & & & & & & & & & & & & \\
\hline & 45 & & & & & + & + & + & + & + & ++ & ++ & ++ & ++ & ++ & ++ & ++ & ++ & ++ & ++ & ++ \\
\hline \multirow{2}{*}{ Shower gel } & RT & & & & & & & & & & & & & & & & & & & & \\
\hline & 45 & & & & & & & & & & & & & & & & & & & & \\
\hline \multirow{2}{*}{ Lotion } & RT & & & & & & & & & & & & & & & & & & & & \\
\hline & 45 & & & & & & & & & & & & & & & & & & & & \\
\hline \multirow{2}{*}{ Body cream } & RT & & & & & & & & & & & & & & & & & & & & \\
\hline & 45 & & & & & & & & & & & & & & & & & & & & \\
\hline
\end{tabular}

Figure IA General appearance.

\begin{tabular}{|c|c|c|c|c|c|c|c|c|c|c|c|c|c|c|c|c|c|c|c|c|c|}
\hline \multirow[b]{2}{*}{ PRODUCTS } & \multirow[b]{2}{*}{$\mathrm{T}^{\circ}\left({ }^{\circ} \mathrm{C}\right)$} & \multicolumn{20}{|c|}{ DAYS } \\
\hline & & 0 & 4 & 7 & 11 & 14 & 18 & 21 & 25 & 29 & 32 & 35 & 39 & 42 & 46 & 49 & 53 & 61 & 68 & 75 & 83 \\
\hline \multirow{2}{*}{ Body scrub } & RT & & & & & & & & & & & & & & & & & & & & \\
\hline & 45 & & & & & + & + & + & + & + & ++ & ++ & ++ & ++ & ++ & ++ & ++ & ++ & ++ & ++ & ++ \\
\hline \multirow{2}{*}{ Shower gel } & RT & & & & & & & & & & & & & & & & & & & & \\
\hline & 45 & & & & & & & & & & & & & & & & & & & & \\
\hline \multirow{2}{*}{ Lotion } & RT & & & & & & & & & & & & & & & & & & & & \\
\hline & 45 & & & & & & & & & & & & & & & & & & & & \\
\hline \multirow{2}{*}{ Body cream } & RT & & & & & & & & & & & & & & & & & & & & \\
\hline & 45 & & & & & & & & & & & & & & & & & & & & \\
\hline
\end{tabular}

Figure IB color.

\begin{tabular}{|c|c|c|c|c|c|c|c|c|c|c|c|c|c|c|c|c|c|c|c|c|c|}
\hline \multirow[b]{2}{*}{ PRODUCTS } & \multirow[b]{2}{*}{$\mathrm{T}^{\circ}\left({ }^{\circ} \mathrm{C}\right)$} & \multicolumn{20}{|c|}{ DAYS } \\
\hline & & 0 & 4 & 7 & 11 & 14 & 18 & 21 & 25 & 29 & 32 & 35 & 39 & 42 & 46 & 49 & 53 & 61 & 68 & 75 & 83 \\
\hline \multirow{2}{*}{ Moisturizer } & RT & & & & & & & & & & & & & & & & & & & & \\
\hline & 45 & & & & & & & & & & & & & & & & & & & & \\
\hline
\end{tabular}

Figure IC odor.

\begin{tabular}{|c|c|c|c|c|c|c|c|c|c|c|c|c|c|c|c|c|c|c|c|c|c|}
\hline \multirow[b]{2}{*}{ PRODUCTS } & \multirow[b]{2}{*}{$\mathrm{T}^{\circ}\left({ }^{\circ} \mathrm{C}\right)$} & \multicolumn{20}{|c|}{ DAYS } \\
\hline & & 0 & 4 & 7 & 11 & 14 & 18 & 21 & 25 & 29 & 32 & 35 & 39 & 42 & 46 & 49 & 53 & 61 & 68 & 75 & 83 \\
\hline \multirow{2}{*}{ Body scrub } & RT & & & & & & & & & & & & & & & & & & & & \\
\hline & 45 & & & & & & & & & & & & & & & & & & & & \\
\hline \multirow{2}{*}{ Solar spray } & RT & & & & & & & & & & & & & & & & & & & & \\
\hline & 45 & & & & & & & & & & & & & & & & & & & & \\
\hline \multirow{2}{*}{ Moisturizer } & RT & & & & & & & & & & & & & & & & & & & & \\
\hline & 45 & & & & & & & & & & & & & & & & & & & & \\
\hline \multirow{2}{*}{ Body cream } & RT & & & & & & & & & & & & & & & & & & & & \\
\hline & 45 & & & & & & & & & & & & & & & & & & & & \\
\hline
\end{tabular}

Modification

No Modification

Figure ID Phase separation.

Figure I Organoleptic results.

Citation: Stephane P. Stability of cosmetic formulations containing UV filters and preservatives, based on physical and chemical parameters. MOJ Toxicol. 20I5; I I I):I2-2I.DOI: I0.15406/mojt.2015.01.00003 


\section{pH, aw and Viscosity Results}

pH: On eight products, only two presented $\mathrm{pH}$ modifications: body scrub (Figure 2A), and moisturizer (Figure 2B). $\mathrm{pH}$ modification are noted when difference between the mean at D0 and the means of the triplicate measures are superior or inferior at $0.255(\mathrm{pH}$-meter sensitivity). Body scrub is the only one to present a $\mathrm{pH}$ decrease at RT

(A)

\section{Body scrub}

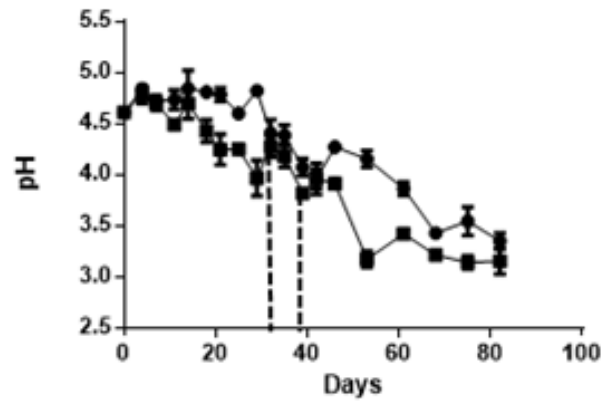

Figure 2 Time dependent variations in $\mathrm{pH}$ values at two temperatures.

(A)

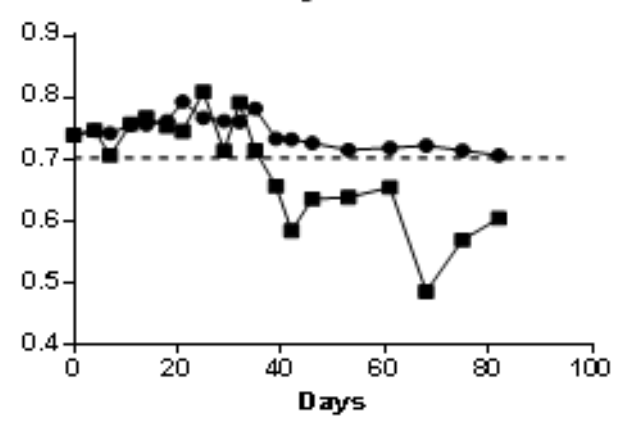

$-25^{\circ} \mathrm{C}$

$-45^{\circ} \mathrm{C}$ and $45^{\circ} \mathrm{C}$. The decrease of $\mathrm{pH}$ appeared at $\mathrm{D} 32$ at $45^{\circ} \mathrm{C}$ and $\mathrm{D} 39$ at RT. Moisturizer has a $\mathrm{pH}$ increase, at $\mathrm{RT}$ and $a 5^{\circ} \mathrm{C}$. Increase appeared at $\mathrm{D} 11$ at $45^{\circ} \mathrm{C}$ and $\mathrm{D} 72$ at RT.

Water activity $\left(\mathbf{a}_{\mathrm{w}}\right)$ : Three on eight products showed a decrease of at least $5 \%$ of their water activity: body scrub, baby shower gel shampoo, and body cream. Decrease was observed on the products stored at $45^{\circ} \mathrm{C}$ refer to (Figure 3 ) for variations in time.

(B)

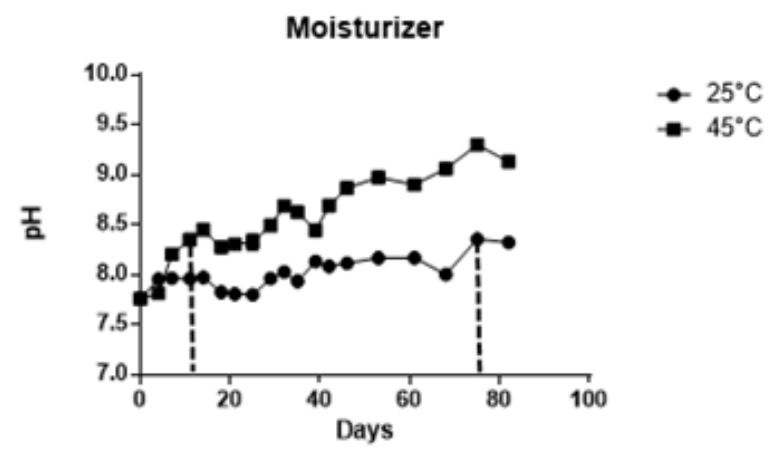

(B)

B aby shower gel shampoo

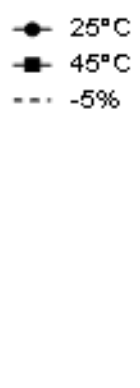

(C)

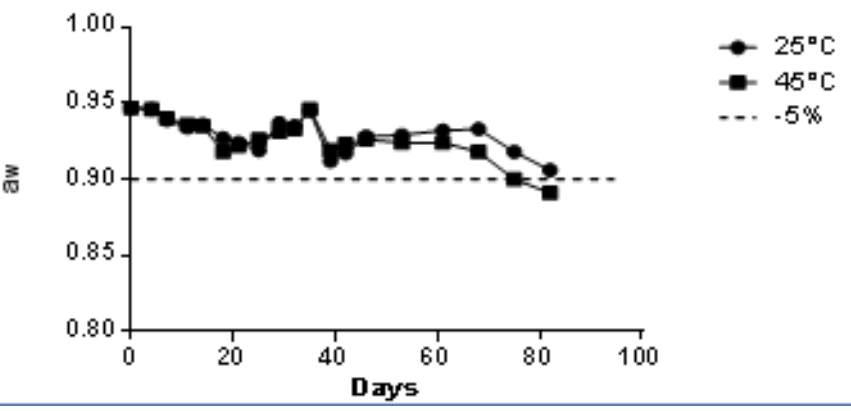

Figure 3 Water activity $\left(a_{w}\right)$ of three cosmetic products at two temperatures.

Viscosity: Regarding to viscosity results, four products showed a trend. Viscosity decreased for moisturizer (Figure 4A) and cleaning gel (Figure 4D) at RT and at $45^{\circ} \mathrm{C}$. For solar spray (Figure 4B) viscosity decreased between D25 and D39, and increased from D42 and was stable to D82. For shower gel (Figure 4E) viscosity increased at $\mathrm{D} 21$ at $45^{\circ} \mathrm{C}$.
According to $\mathrm{pH}$, aw and viscosity results, six formulas showed modification: body scrub, moisturizer, body cream, baby shower gel shampoo, cleansing gel and solar spray. Among these formulas, three had undergone organoleptic deterioration: body scrub, moisturizer and body cream. Baby shower gel shampoo has shown decrease of at least $5 \%$ of water activity at D39, D61 and D82, but no other 
observation appeared on baby shower gel shampoo. No interpretation can be done on this single observation for this formula. The fluidity changes observed by general appearance criteria can be check up with the viscosity modification monitored by a viscometer for moisturizer and solar spray. However, other viscosity modification no visible by naked eye can be determined only by apparatus, especially for shower gel, and cleansing gel. For these products, no changes have occurred for general aspect or phase separation, so physical instability cannot be determinate.

In regards to physico-chemical results, same formula that previous organoleptic observations have significant modification: body scrub, moisturizer and body cream.
(A)

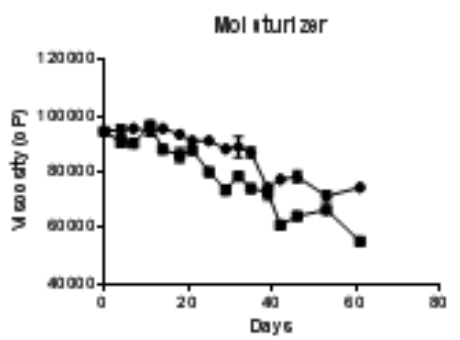

(C)

Baby thower gel tham poo

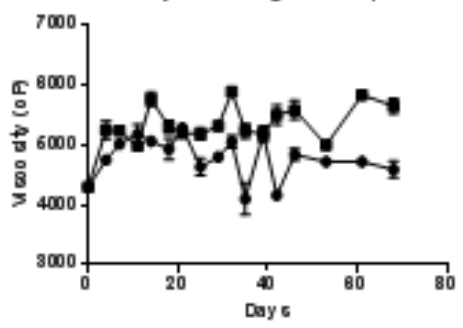

(日)

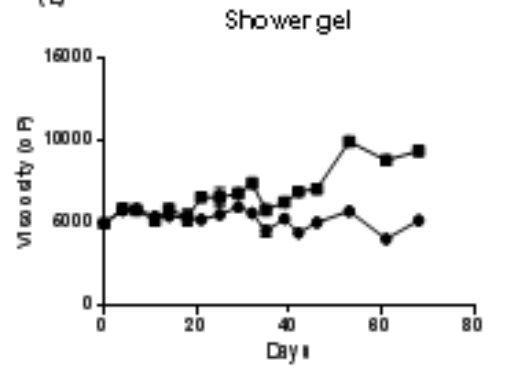

(B)

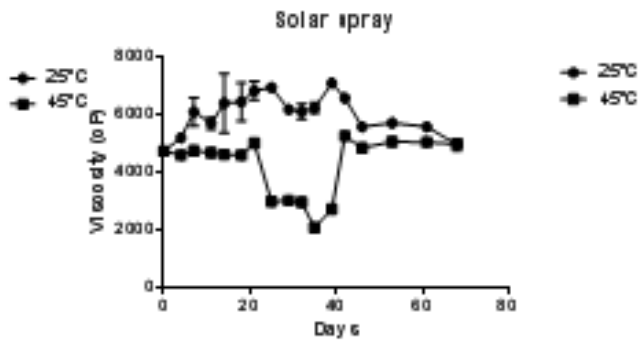

(D)

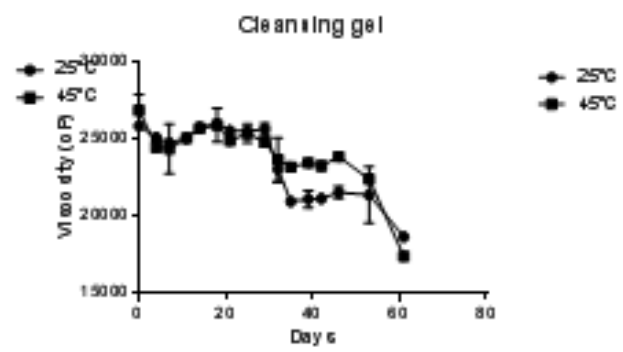

$-25^{\circ} \mathrm{C}$

$25^{\circ} \mathrm{C}$

Figure 4 Time dependent variations in viscosity at two temperatures.

\section{Analytical results}

Eleven molecules have been followed, only four have shown variations of concentration (Figure 5). Methylparaben, propyl paraben, salicylic acid, and benzoic acid. These preservatives were analyzed for these following formulas: moisturizer, cleansing gel, and body cream. No diminutions have been observed for UV filters or for the other preservatives.

a) For moisturizer: A 10\% diminution of methyl paraben appeared at $\mathrm{D} 40$ at $\mathrm{RT}$ and at $\mathrm{D} 19$ at $45^{\circ} \mathrm{C}$. A $10 \%$ diminution of propyl paraben appeared at $\mathrm{D} 76$ for $\mathrm{RT}$ and at $\mathrm{D} 76$ at $45^{\circ} \mathrm{C}$.

b) For cleansing gel: A 10\% diminution of methyl paraben appeared at $\mathrm{D} 43$ at $\mathrm{RT}$ and $45^{\circ} \mathrm{C}$. A $10 \%$ diminution of propyl paraben appeared at $\mathrm{D} 36$ for $\mathrm{RT}$ and at $\mathrm{D} 33$ at $45^{\circ} \mathrm{C}$. A $10 \%$ diminution of salicylic acid appeared at RT and $45^{\circ} \mathrm{C}$ at D40.

c) For body scrub: A 10\% diminution of benzoic acid appeared at RT and $45^{\circ} \mathrm{C}$, from D19 the concentration is outside the validate linearity range and below the limit of quantification.

In general, for each formula, decreases of preservatives concentrations have appeared first at the higher temperature, or appeared at the same time at $45^{\circ} \mathrm{C}$ and RT. No diminution was observed first at RT.

\section{Overall results}

First, the physico-chemical tests are different depending on the type of matrices. A selection of specific criteria must be choosing in advance. All criteria are not applicable to all types of matrixes (Table 5). For example: phase difference is specific to emulsion because of 
their internal structure composed of one or more fluid; $a_{w}$ is specific to formula which contains a minimum $\%$ of water; $\mathrm{pH}$ could not be measured on the body oil due to the flacks; viscosity could not be measured on body cream due to its structure.

In conclusion to this first observation, it is necessary before any study of stability that criteria must be chosen depending on the type of matrices. Also preliminary tests should be performed, in order to know what the best protocol and which equipment choose for the matrix. According to the results (Table 5) all criteria provide information on at least on type of matrices. We can say that all criteria studied in this work are necessary to stability test. However, some criteria require additional measurement, especially: $a_{w}$, viscosity, and analytical measurements. In this study, according to standard ISO 29621:2012 which sets up limits of $\mathrm{a}_{\mathrm{w}}, \mathrm{a} \mathrm{a}_{\mathrm{w}}<0.6$ defines hostile medium to microbial growth, all products are exposed to microbial contamination and it's possible to quantified the decrease of water
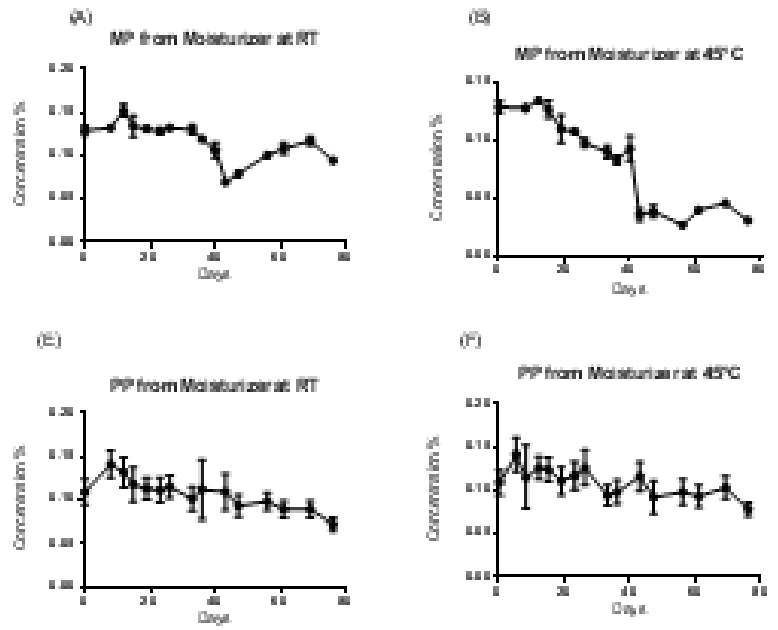

$\theta$
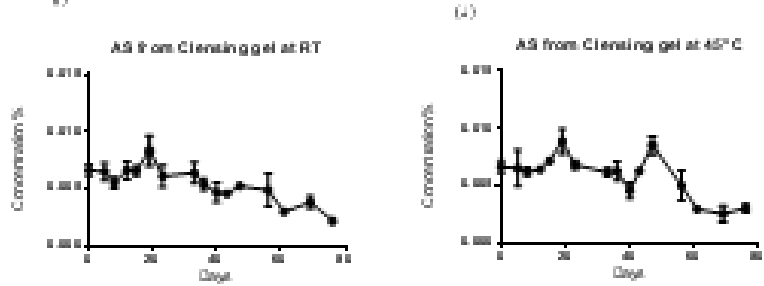

Figure 5 Time dependent degradation of MP, PP, SA and BA at two temperatures.

In regard of the ingredients of the formulas it is possible to make some assumption about the instability of the two most critical matrices: body scrub and moisturizer. First, body scrub contains $94.45 \%$ of oil phase, with two types of oil: Helianthus Annusseed oil and Hydrogenated coconut oil. Most common instability in this type of formula is rancidity. Indeed Helianthus Annusseed oil is composed of $89 \%$ unsaturated acids (oleic acid $30 \%$, linoleic acid $59 \%$ ), that are subject to oxidation. A rise of temperature promotes the oxidation of lipids. Lipid oxidation is favored by higher temperature, which leads to secondary products resulting to hydro peroxide decomposition and separation of allylic hydrogen's. The most common secondary products of oleic acid and linoleic acid are carboxylic acids. $\mathrm{pH}$ diminution, activity. However, this measure can be completed by challenge tests or total microbial count to specify microbiological modifications. ${ }^{16-19}$ Viscosity can be specified by the nature of the flow with accurate measures using a software program. The analytical result provides information on concentration variation of actives compounds that is the objective of this work, but it can be completed by determination of degradation products and their toxicity. According to the organoleptic observations body scrub and moisturizer are unattractive for the consumer at RT condition from respectively D21 and D42. Theoretical PAO calculated on the base of the ANSM guidelines for these products are respectively six months and five months, result showed that these periods are not proved experimentally ${ }^{3}$ Shower gel, body cream, lotion, and solar spray do not present physico-chemical modifications or actives degradation. Temperature has an impact on their stability but it cannot be concluded on their degradation at long term and their shelf life. Make up products (mascara, lipstick, nail polish) and body oil, present any sign of degradation visible to the naked eye. (c)

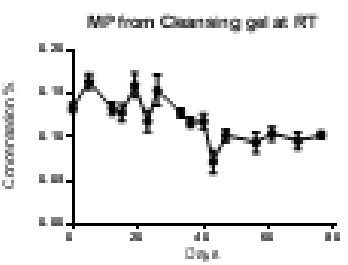

(c)

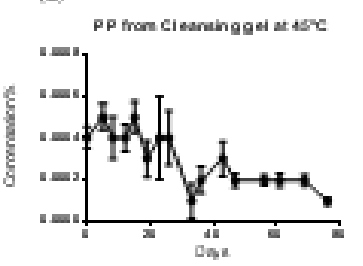

$(0)$

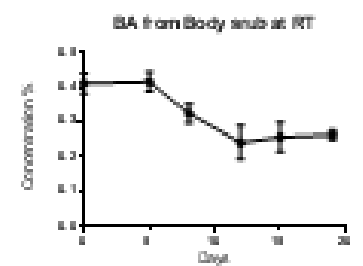

cis

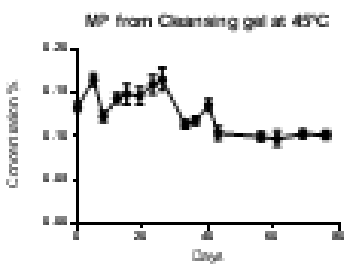

ati

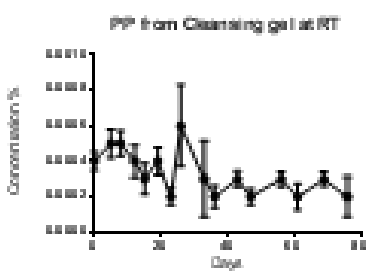

a)

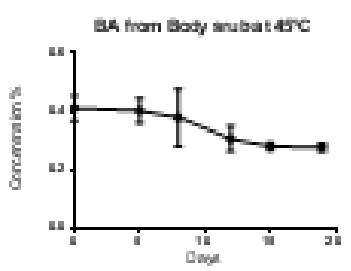

general aspect and color modification are three parameters explains by the rancidity. Phase separation is due to water evaporation as we can see by the diminution of $\mathrm{a}_{\mathrm{w}}$ (Figure $3 \mathrm{~A}$ ) Temperature accelerates all these instabilities. Secondary, for moisturizer, odor modification has appeared 54 days before $\mathrm{pH}$ increase at $\mathrm{RT}$, so $\mathrm{pH}$ measurement cannot explain totally odor modification. In regards to moisturizer composition, formula contains $3 \%$ of urea. Decomposition of urea was studied by Jian Ping Chen et al., ${ }^{20}$ and explained that urea is a thermally-labile compound which has a complicated thermal behavior. The thermal decomposition proceeded via several stages and a novel reaction produce carbon dioxide and ammonia. $\mathrm{pH}$ of ammonia is about 11 and can explain the $\mathrm{pH}$ increased (Figure 2B) and the 
strong and spicy ammoniac odor. In addition to urea degradation, degradation of moisturizer preservatives has been observed (Figure 5A,B,E,F). Methylparaben decreased from $0.129 \%$ to $0.094 \%$ at RT and to $0.031 \%$ at $45^{\circ} \mathrm{C}$. Propyl paraben decreased from $0.109 \%$ to $0.072 \%$ at RT and to $0.078 \%$ at $45^{\circ} \mathrm{C}$. Temperature accelerates the degradation of paraben in two formulas: Moisturizer and Cleansing gel. Action of temperature on this type of molecules was determined by forced degradation using a micro reactor flow system in the Syrris application note in 2007. ${ }^{21}$ Decrease of preservatives concentration leads to a microbiological risk which can result in a modification of formula (acidity increase due to the proliferation of bacteria, microbial load increase). Paraben degradation can have an impact on the consumer's safety: increase of the skin flora and skin infection.

Table 5 Time dependent unfavorable modifications in below mentioned cosmetic products

\begin{tabular}{|c|c|c|c|c|c|c|c|c|c|c|c|c|c|c|c|c|c|c|}
\hline \multirow[b]{2}{*}{ Formula } & \multirow[b]{2}{*}{$\mathbf{T}^{\circ}$} & \multicolumn{4}{|c|}{ Organoleptic criteria } & \multicolumn{3}{|c|}{$\begin{array}{c}\text { Physico-chemical } \\
\text { parameters }\end{array}$} & \multicolumn{10}{|c|}{ Active compound } \\
\hline & & $A$ & $B$ & $C$ & $D$ & $p H$ & $a \mathrm{ar}$ & $V$ & $A B$ & $S A$ & $B A$ & ОСТО & BEMO & BENZO 4 & $M P$ & $P P$ & PHE & CHLOR \\
\hline \multirow{2}{*}{ Body scrub } & RT & & & & & & & NA & & NA & NA & NA & NA & NA & NA & NA & NA & NA \\
\hline & 45 & & & & & & & NA & & NA & NA & NA & NA & NA & NA & NA & NA & NA \\
\hline \multirow{2}{*}{ Shower gel } & RT & & & & NA & & & & NA & NA & & NA & NA & NA & NA & NA & NA & NA \\
\hline & 45 & & & & NA & & & & NA & NA & & NA & NA & NA & NA & NA & NA & NA \\
\hline Body oil & RT & & & & NA & NA & NA & NA & NA & NA & NA & NA & NA & NA & NA & NA & NA & NA \\
\hline \multirow{2}{*}{ Body cream } & RT & & & & & & & NA & NA & NA & NA & NA & NA & NA & NA & NA & & \\
\hline & 45 & & & & & & & NA & NA & NA & NA & NA & NA & NA & NA & NA & & \\
\hline \multirow{2}{*}{ Cleansing gel } & RT & & & & & & & & NA & & NA & NA & NA & NA & & & NA & NA \\
\hline & 45 & & & & & & & & NA & & NA & NA & NA & NA & & & NA & NA \\
\hline \multirow{2}{*}{$\begin{array}{l}\text { Baby shower } \\
\text { gel shampoo }\end{array}$} & RT & & & & & & & & NA & NA & NA & NA & NA & NA & NA & NA & NA & \\
\hline & 45 & & & & & & & & NA & NA & NA & NA & NA & NA & NA & NA & NA & \\
\hline Lotion & RT & & & & NA & & & NA & NA & NA & NA & NA & & NA & NA & NA & NA & NA \\
\hline \multirow{2}{*}{ Solar spray } & RT & & & & & & & & NA & NA & NA & & & NA & NA & NA & NA & NA \\
\hline & 45 & & & & & & & & NA & NA & NA & & & NA & NA & NA & NA & NA \\
\hline \multirow{2}{*}{ Moisturizer } & RT & & & & & & & & NA & NA & NA & NA & NA & NA & & & NA & NA \\
\hline & 45 & & & & & & & & NA & NA & NA & NA & NA & NA & & & NA & NA \\
\hline \multirow{2}{*}{ Lipstick } & RT & & & & NA & NA & NA & NA & NA & NA & NA & NA & NA & NA & NA & NA & & NA \\
\hline & 45 & & & & NA & NA & NA & NA & NA & NA & NA & NA & NA & NA & NA & NA & & NA \\
\hline \multirow{2}{*}{ Mascara } & RT & & & & NA & NA & NA & NA & NA & NA & NA & NA & NA & NA & NA & NA & & NA \\
\hline & 45 & & & & NA & NA & NA & NA & NA & NA & NA & NA & NA & NA & NA & NA & & NA \\
\hline \multirow{2}{*}{ Nail Polish } & RT & & & & NA & NA & NA & NA & NA & NA & NA & NA & NA & NA & NA & NA & NA & NA \\
\hline & 45 & & & & NA & NA & NA & NA & NA & NA & NA & NA & NA & NA & NA & NA & NA & NA \\
\hline
\end{tabular}

\section{Conclusion}

In this work, only two products on twelve showed instability under normal conditions and accelerated condition. One composed of an oily phase: body scrub and an emulsion: moisturizer. For these two products, theoretical PAO was estimated and compared to experimentation. For body scrub theoretical PAO was 6 months, which is not in correlated with the study. Body scrub is not attractive after 14 days, its structure is broken. Moreover, its $\mathrm{pH}$ around 3.5 is beyond the limits of tolerance for the skin. For moisturizer theoretical PAO is 5 months. In regards to experimentation, odor makes the product unusable after 14 days and predicts a degradation of urea, $\mathrm{pH}$ around 9 is not appropriate for leave-on product. Preservative concentration decreased fewer than $10 \%$ after 40 days. In both cases, results have shown that theoretical PAO are not proved experimentally. For other matrices, six products which are mainly emulsions have shown instability at $45^{\circ} \mathrm{C}$, and the four other products, which are make-up and body oil, no modification was observed. Emulsion appears to be more sensitive to heat. In this study, eight parameters have been monitored; all parameters have given information at least on one formula.

Product degradation studies are important tests in order to identify preservatives degradation: methylparaben, propyl paraben, salicylic acid and benzoic acid. Decreasing of their concentrations reflected degradations that can have an important impact on microbiological safety and consequences on consumer safety. Analytical tests for any cosmetic products have their importance on stability evaluation to be sure that the product keep sits efficiency and ensures the safety of consumer. To finish, the understanding of chemical reactions that may appear under different stress or time storage, is a point that must be systematically integrate on the evaluation of shelf life product. Moreover, temperature has a catalytic role in many reactions; its effect has been demonstrated in the case of body scrub during oxidation and degradation of benzoic acid, and for moisturizer on the degradation of methylparaben and propyl paraben. For the others matrixes high temperature has activated reactions of instability but its prediction at room temperature cannot be proven. Use of elevated temperature to increase the interaction is a powerful factor to shorten the length of time required for stability test. The same experimentation can be managed including others external stresses such as light, moisture, voluntary contamination...in order to set up the significant factors combination for accelerated stability test conditions and identify other type of degradation as photo degradation.

\section{Acknowledgements}

None.

\section{Conflict of interest}

The author declares no conflict of interest. 


\section{References}

1. European Commission. Regulation No $1223 / 2009$ of the European parliament and of the council on cosmetic products. 2009.

2. Scientific Committee on Consumer Safety. The SCCS's notes guidances for the testing of cosmetic substances and their safety evaluation. 8th revision. 2012. p. 1-133.

3. ANSM. Recommendation concerning the estimation of the period after opening (PAO). 2006.

4. Liu YS, Ying GG, Shareef A, et al. Photo stability of the UV filter benzophenone-3 and its effect on the photo degradation of benzotriazole in water. Environmental Chemistry. 2011;8(6):581-588.

5. Salvador A, Pascual Martii MC, Adell JR, et al. Analytical methodologies for atomic spectrometric determination of metallic oxides in UV sunscreen creams. J Pharm Biomed Anal. 2000;22(2):301-306.

6. Mori K, Itoh K, Suzuki S, et al. Analysis of ultraviolet absorbers in cosmetics by two dimension NMR spectroscopy. Japanese Journal of Toxicology and Environmental Health. 1996;42(1):60-66.

7. Cheng J, Li YS, Roberts RL, et al. Analysis of 2-ethylhexyl-pmethoxycinnamate in sunscreen products by HPLC and Raman spectroscopy. Talanta. 1997;44(10):1807-1813.

8. Chisvert A, Salvador A, Pascual-Marti MC. Simultaneous determination of oxybenzone and 2-ethylhexyl 4-methoxycinnamate in sunscreen formulations by flow injection-isodifferential derivative ultraviolet spectrometry. Analytical Chimica Acta. 2001;428(2):183-190.

9. Chisvert A, Salvador A, Pascual-Martii MC, et al. Efficient flow injection and sequential injection methods for spectrophotometric determination of oxybenzone in sunscreens based on reaction with Ni(II). Fresenius $J$ Anal Chem. 2001;369(7-8):684-689.

10. Felix T, Hall BJ, Brodbelt JS. Determination of benzophenone-3 and metabolites in water and human urine by solid-phase microextraction and quadrupole ion trap GC \pm MS. Analytical Chimica Acta. 1998;371(23):195-203.
11. Vaugelade S De, Thomas C, Pirnay S. Validation of screening method in GC/MS and determination of UV filters in LC/UV, for the stability of cosmetics. T04 Microbiology and Toxicology poster session at SMAP congress (Lyon). 2014.

12. Rastogi SC, Jensen GH. Identification of UV filters in sunscreen products by high performance liquid chromatography diode-array detection. Journal of Chromatography. 1998;828(1-2):311-316.

13. Guaratini T, Mirela Gianeti D, Campos MBGM. Stability of cosmetic formulations containing esters of vitamins $\mathrm{E}$ and $\mathrm{A}$ : chemical and physical aspects. Int J Pharm. $2006 ; 327(1-2): 12-16$.

14. Anchisi C, Maccioni AM, Sinico C, et al. Stability studies of new cosmetic formulations with vegetable extracts as functional agents. Farmaco. 2001;56(5-7):427-431.

15. Glampedaki P, Dutschk V. Stability studies of cosmetic emulsions prepared from natural products such as wine, grape seed oil and mastic resin. Colloids and Surfaces A: Physicochemical and Engineering Aspects. 2014;460:306-311.

16. ISO 29621. Cosmetics, Microbiology - Guidelines for the risk assessment and identification of microbiologically low-risk products. 2010.

17. Lafosse S, Debray M, Pirnay S. Determination of significant factors in order to assess the stability of cosmetic products in regards with the use/ or not of challenge tests. Toxicology Letters. 2011;205:S264-S265.

18. Berthele H, Sella O, Lavarde M, et al. Determination of the influence of factors (ethanol, $\mathrm{pH}$ and $\mathrm{Aw}$ ) on the preservation of cosmetics using experimental design. Int J Cosmet Sci. 2013;36:54-61.

19. Ghalleb S, De Vaugelade S, Sella O, et al. Predictive microbiology for cosmetics based on physicals, chemicals and concentration parameters. Int J Cosmet Sci. 2014;37(1):70-75.

20. Ping Chen J, Isa K. Thermal decomposition of urea and urea derivatives by simultaneous TG/(DTA)/MS. J Mass Spectrom Soc Jpn. 1998;46(4):299-303

21. Syrris. The forced degradation (De-esterification) of parabens using a microreactor flow system. Application note number 14. 2007. 